\title{
O setor de pellets de madeira no Brasil
}

\section{Dorival Pinheiro Garcia ${ }^{1^{*}}$, José Cláudio Caraschi ${ }^{2}$, Gustavo Ventorim²}

\author{
${ }^{1}$ Programa de Pós-Graduação em Engenharia Mecânica - Materiais Lignocelulósicos, UNESP-Universidade Estadual Paulista \\ "Júlio de Mesquita Filho", Guaratinguetá, SP, Brasil. \\ ${ }^{2}$ Departamento de Tecnologia da Madeira, UNESP-Universidade Estadual Paulista "Júlio de Mesquita Filho", Itapeva, SP, \\ Brasil.
}

\begin{abstract}
RESUMO Os acordos firmados na Conferência do Clima da ONU (COP21), em dezembro de 2015, sugerindo substituição de combustíveis fósseis por energias renováveis e de baixa emissão de carbono, intensificaram a demanda internacional por pellets de madeira. O Brasil é apontado como uns dos promissores países exportadores deste biocombustível. Porém, há poucos dados sobre a indústria e o setor de pellets brasileiro. Assim, o objetivo desse estudo foi disponibilizar informações como as aplicações mais importantes, preços de venda, produção e os principais desafios deste setor industrial no Brasil. Realizou-se uma pesquisa com todos os produtores brasileiros, por meio da aplicação de um questionário, desenvolvido por intermédio do recurso de formulários on line do Google Forms. O índice de resposta de 100\% permitiu fazer inferências de interesse sobre o setor de pellets, concluindo que é um mercado ainda jovem, produziu 75 mil toneladas em 2015 e apresenta três problemas principais: baixo consumo interno, alto custo da energia elétrica e desconhecimento do produto pelos consumidores.
\end{abstract}

Palavras-chave: combustível sólido; bioenergia; pinus para energia; COP21.

\section{The wood pellets sector in Brazil}

\begin{abstract}
Agreements reached at the UN Climate Conference (COP21) in December 2015 suggesting replacement of fossil fuels with renewable and low-carbon energy, had intensified the international demand for wood pellets. Brazil is one of the most promising countries to export this biofuel. However, there is few data about the Brazilian industry of pellets. Therefore, the objective of this study was to provide information such as the most important applications, sales prices, production and the main challenges of this industrial sector in Brazil. A survey was conducted with all Brazilian manufacturers of pellets through the application of a questionnaire developed using the Google Forms online forms resource. The $100 \%$ response index allowed us to make inferences of interest on the pellet sector, concluding that it is still a young market. This market produced 75,000 tonnes in 2015 and presents three main problems: low internal consumption, high cost of electric power and a lack of knowledge about the product by the consumers.
\end{abstract}

Keywords: Solid fuel; bioenergy; pinus for fuel; COP21.

\section{Introdução}

Os pellets (Figura 1) são biocombustíveis sólidos que podem ser produzidos a partir de resíduos da indústria agroflorestal, como a serragem ou maravalha de madeira, a casca de arroz e o bagaço de cana. Eles são compactados com baixo teor de umidade ( $\mathrm{TU}<10 \%)$, permitindo elevada densidade energética (GARCIA et al., 2016b). A geometria regular e cilíndrica dos pellets permite ótima fluidez facilitando a automatização de processos comerciais e industriais de queima do produto. Além disso, é uma fonte de energia renovável e de fácil manuseio que ocupa pouco espaço na armazenagem (GARCIA et al., 2013).

A utilização dos pellets traz benefícios ao meio ambiente por ser considerado energia de baixo carbono, ou seja, quase

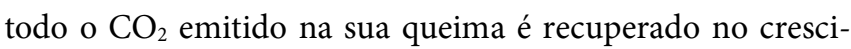
mento da biomassa florestal, minimizando as emissões de gases do efeito estufa (GARCIA et al., 2016a; KONG et al., 2013; LIU et al., 2010). Por esse motivo, durante os últimos anos, esse biocombustível sólido se transformou em um importante recurso energético mundial, especialmente na Europa, onde 
seu mercado é estável e passa por um rápido desenvolvimento (GARCIA et al., 2016a). De acordo com Toscano et al. (2014), cerca de 9,2 milhões de toneladas de pellets foram consumidos pelos países europeus em 2009, 14,4 milhões em 2011 e espera-se um consumo de 50,0 milhões de toneladas para 2020 (AEBIOM, 2014; BISWAS et al., 2011; SELKIMÄKI et al., 2010). Os pellets de madeira já são considerados um dos maiores produtos de biomassa sólida comercializados internacionalmente (GARCIA, 2014b). Quanto à produção deste biocombustível no Brasil, os dados de 2014 divergem entre 49.390 toneladas por ano ( $\left.\mathrm{t} \mathrm{a}^{-1}\right)$ (GARCIA et al., 2016b), $47.000 \mathrm{t} \mathrm{a}^{-1}$ (INDÚSTRIA BRASILEIRA DE ÁRVORES - IBÁ, 2015) e $62.000 \mathrm{t} \mathrm{a}^{-1}$ (FORTI; HEMRARD, 2014).

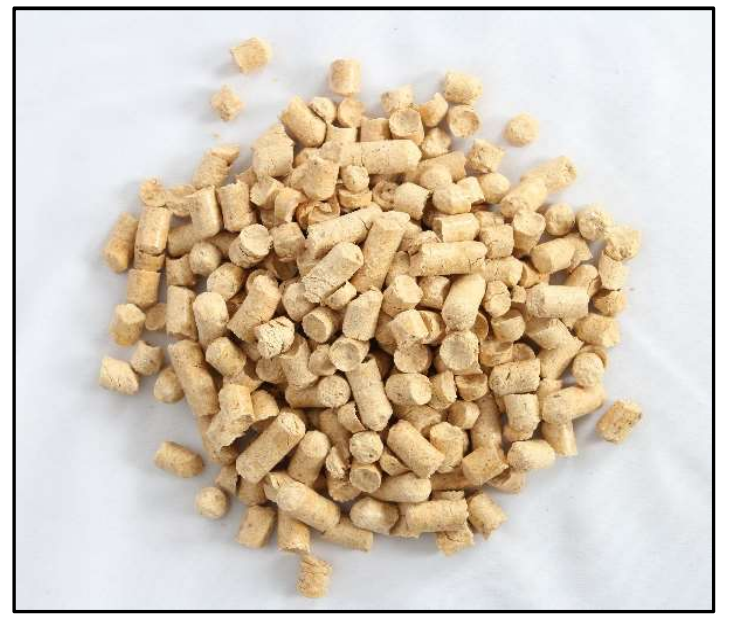

Figura 1. Biocombustíveis pellets de madeira.

Figure 1. Biofuels wood pellets.

Por ser um combustível renovável e menos poluente que os derivados do petróleo, os pellets têm sido utilizados por países que precisam diminuir suas emissões de gases do efeito estufa (GEE) para atender aos acordos firmados no Protocolo de Kyoto (VASSILEV et al., 2010) e ratificados na Conferência do Clima (COP21), que ocorreu na França, em dezembro de 2015 (ADAMS; LINDEGAARD, 2016; LASCHI et al., 2016).
Depois que os pellets se tornaram commodities negociada em todo o mundo, o Brasil é naturalmente apontado como uns dos principais países neste segmento por conta de suas características edafoclimáticas propícias para a produção de biomassa florestal. Por isso, cresceu a necessidade de se ter dados mais confiáveis deste promissor mercado de energia renovável, pois são poucos os artigos que abordam a indústria de pellets de madeira no Brasil. Assim, o objetivo desse estudo foi disponibilizar dados e informações do mercado de pellets de madeira como as principais aplicações, preços, produção total, matéria-prima utilizada e os principais desafios deste setor industrial no Brasil.

\section{Material e Métodos}

Para obter os resultados aplicou-se um questionário desenvolvido por meio do recurso de formulários on line do Google Forms. Optou-se por utilizar este recurso devido à sua facilidade de distribuição, preenchimento e apuração dos resultados. Além disso, Heidemann et al. (2010) apontam outras vantagens dos formulários on line: custo (é gratuito), facilidade de uso (não requer conhecimentos específicos) e interface amigável (semelhantes aos aplicativos usuais).

Um convite com o link do formulário com as perguntas foi enviado, via e-mail, aos treze produtores atuais de pellets do Brasil. Porém, para impedir que o formulário fosse modificado, apagado ou compartilhado inadvertidamente, sua edição só era permitida ao usuário que o criou. Todas as perguntas exigiam respostas obrigatórias, de modo que o formulário só poderia ser enviado com todas as respostas. As perguntas foram elaboradas de três tipos diferentes: (a) tipo texto, para questões dissertativas abertas; (b) múltipla escolha, para selecionar somente uma das opções apresentadas e (c) caixas de seleção, que permite que o respondente escolha várias alternativas de um elenco de opções. 
A pesquisa foi realizada entre os meses de janeiro e março de 2016 e iniciou-se com o envio de um link do formulário as treze empresas produtoras de pellets do Brasil. O formulário continha dez perguntas sobre o mercado de pellets de madeira no Brasil. Das treze empresas procuradas, somente uma não respondeu às perguntas, mas suas principais informações foram obtidas, posteriormente, via telefone. Assim, obteve-se um índice de resposta de $100 \%$, resultado excelente, dado o método de aplicação do questionário e a dispersão das indústrias pelas diversas regiões do Brasil.

A análise dos dados, elaborada por meio de estatística descritiva simples, após sua depuração e comparação com as informações da literatura, permitiram o alcance dos objetivos propostos com generalizações sobre a população pesquisada.

\section{Resultados e Discussão}

Com base nas análises das respostas pôde-se fazer inferências de interesse para atingir o objetivo deste estudo. Assim, observa-se na Tabela 1, que as plantas industriais de pellets existentes no Brasil são relativamente jovens, foram criadas a partir de 2004 e 69\% delas surgiram depois de 2012. Essas empresas produtoras têm, portanto, pouco mais de 12 anos de atuação no mercado. Já na Europa e América do Norte, o surgimento desse biocombustível, ocorreu há mais de 35 anos, no início da década de 80 , para solucionar a grave crise do petróleo, que limitou sua produção e triplicou o seu preço (OBERNBERGER; THEK, 2004). O mercado dos pellets de madeira no Brasil tem, em relação a estes países, uma defasagem de mais de 23 anos. O efeito desse atraso pode ser percebido quanto à tecnologia das peletizadoras utilizadas na produção dos pellets (as importadas são mais eficientes que as nacionais), no conhecimento adquirido sobre esse biocombustível e na sua utilização no mercado interno e externo (GARCIA et al., 2016a)
Em 2004, apenas duas empresas fabricavam pellets no Brasil e, atualmente, são treze. Nota-se a expansão deste mercado, no Brasil e no Mundo, que pode ser explicado pela crescente demanda por fontes de energia renovável que sejam alternativas ao petróleo e seus derivados (GARCIA et al., 2016b).

Tabela 1. Indústrias de pellets no Brasil.

Table 1. Pellet Industries in Brazil.

\begin{tabular}{cc}
\hline $\begin{array}{c}\text { Ano de início } \\
\text { da produção }\end{array}$ & $\begin{array}{c}\text { Quantidade de empre- } \\
\text { sas produtoras de pellets de } \\
\text { madeira }\end{array}$ \\
\hline 2004 & 2 \\
2005 & 1 \\
2007 & 1 \\
2012 & 3 \\
2013 & 1 \\
2014 & 3 \\
2015 & 2 \\
\hline Total & $\mathbf{1 3}$ \\
\hline
\end{tabular}

De acordo com as informações levantadas, todas as empresas utilizam os resíduos de Pinus (na forma de serragem, pó de serra ou maravalha) das indústrias madeireiras como principal matéria-prima do processo de peletização. Os resíduos de eucaliptos também foram citados, entretanto, os próprios produtores informaram que, por ser madeira mais dura do que o Pinus, torna o processo de peletização mais caro e mais lento. Além disso, a utilização dessa folhosa diminui a vida útil das matrizes e dos rolos das peletizadoras, por conta do desgaste excessivo causado pelo atrito mecânico. A utilização de equipamentos mais robustos, com uma fase de condicionamento com vapor superaquecido, tem sido utilizado para processar esta matéria-prima. Utilizar misturas de espécies florestais, contendo 70\% Pinus e 30\% eucalipto, é outra solução prática que minimiza o desgaste e prolonga a vida útil da matriz de peletização, assim como já relataram outros autores (HOLM et al., 2006; ÖHMAN et al., 2004; SERRANO et 
al., 2011; VERMA et al., 2012). Nas empresas brasileiras, 23\% informaram utilizar essa mistura na produção dos pellets.

A escolha da matéria-prima está relacionada à distribuição geográfica das empresas e a disponibilidade de biomassa florestal residual próximo à planta industrial. Os resíduos da madeira de Pinus, matéria-prima utilizada por todos os produtores brasileiros, é um subproduto das indústrias madeireiras da região onde a fábrica de pellets está localizada. As regiões Sul e Sudeste, foco da produção de pellets no país, concentram $73 \%$ dos resíduos das indústrias de madeira processadas no Brasil (SCHNEIDER et al., 2012). Além disso, estão nessas regiões os maiores percentuais de áreas com plantios florestais de Pinus do país, com 84,6\% (IBÁ, 2015). Outras biomassas vegetais como o bagaço de cana, capim-elefante, bambu e acácia-negra não foram citadas, apesar de constarem como opção de resposta no formulário. Conclui-se, então, que no Brasil em 2015, somente pinus e eucalipto foram utilizados para a produção de biocombustíveis na forma de pellets. Nenhuma empresa citou o uso de toras de madeira no processo de fabricação dos pellets, assim, pode-se inferir que as indústrias só utilizam os resíduos das indústrias madeireiras, na forma de serragem e maravalha.

Com relação à produção média anual de pellets, os produtores informaram que produziram 75.000 toneladas em 2015 (Tabela 2). Desta forma, conclui-se que houve um significativo aumento $(51,85 \%)$ da produção, em relação ao ano de 2014, decorrentes do maior volume de pellets de madeira destinados ao mercado exportação. Além disso, em 2015, mais dois produtores de pellets obtiveram o selo de qualidade para exportação ENplus (ISO, 2014), totalizando três produtores certificados, para pellets tipo A1, de uso residencial, favorecendo o aumento das vendas para o mercado externo.

No entanto, Garcia et al. (2016b) argumentaram que, apesar do crescimento da produção, a participação do Brasil no mercado internacional é pouco significativa. Só os Estados Unidos, em 2014, produziram 6,9 milhões de toneladas de wood pellets. A produção brasileira, no mesmo ano, alcançou menos de $1 \%$ do que fabricaram os norte-americanos (FORTI; HEMRARD, 2014).

Tabela 2. Produção anual de pellets de madeira no Brasil.

Table 2. Annual production of wood pellets in Brazil.

\begin{tabular}{ccc}
\hline Ano & Produção anual (t) & Referência \\
\hline 2011 & 50.080 & \\
2012 & 56.580 & Garcia et al. (2016b) \\
2013 & 61.500 & \\
2014 & 49.390 & este estudo \\
\hline 2015 & 75.000 & \\
\hline
\end{tabular}

Os dados, compilados dos formulários, revelam ainda que a maior parte das indústrias peletizadoras $(92,3 \%)$ é de pequeno porte (Figura 2), com produção estimada de até 8 mil toneladas por ano. Somente uma indústria brasileira $(7,69 \%)$ tem produção anual superior a $30 \mathrm{mil} \mathrm{t}^{-1}$. Os estudos de Shahrukh et al. (2016) mostraram que, as empresas com capacidade de produção a partir de 50 mil toneladas por ano, por meio da economia de escala, conseguem otimizar sua produção provocando um aumento na quantidade total produzida, sem um aumento proporcional no custo de produção. Assim, as pequenas indústrias de pellets no Brasil, por não possuírem escala de produção, têm baixa competitividade, o que limita a utilização do biocombustível no mercado interno, que ainda é pouco desenvolvido no país.

Além disso, os grandes consumidores europeus como a Itália e o Reino Unido, por exemplo, exigem conformidade dos pellets com a norma ISO 17225-2 (ISO, 2014), com critérios rígidos para a qualidade dos pellets, sobretudo tipo A1 para uso residencial. A tecnologia dos equipamentos nacionais, em sua maioria, não alcançam estas especificações de qualidade e, por isso, não conseguem obter o selo exigido para 
as exportações (DIAS et al., 2012; GARCIA, et al., 2016a). Por isso, apenas $23,07 \%$ dos produtores consultados estão negociando o biocombustível com este mercado externo.

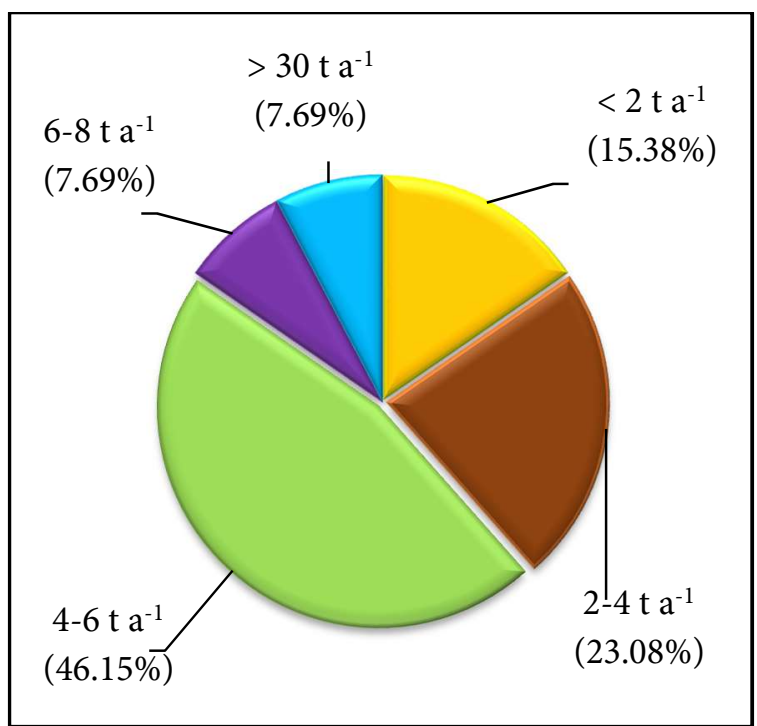

Figura 2. Produção anual de pellets de madeira (\% das empresas com esta produção).

Figure 2. Annual production of wood pellets (\% of companies with this production).

Na questão dos preços praticados no Brasil (Figura 3), os dados indicaram que os pellets de madeira são vendidos em uma faixa de preços de $\mathrm{R} \$ 400,00$ a $\mathrm{R} \$ 600,00$ reais por tonelada, com uma média de R $\$ 471,15$ (FOB-Free on board), para pellets retirados na fábrica.
Estudo de Garcia (2014a), sobre os preços dos pellets de madeira no Brasil, apontou que os preços variaram entre $\mathrm{R} \$$ 390,00 e R\$ 650,00 a tonelada, para as vendas a granel em sacos big bags, retirados na fábrica. Para o mercado externo, os wood pellets de melhor qualidade, tipo A1 Premium para uso residencial, alcançam valores médios de 140,00 €/t (a granel) e 170,00 €/t (ensacado, 15,0 kg), com entrega até porto da Itália (SHAHRUKH et al., 2016).

Para facilitar o carregamento e descarregamento, as empresas exportadoras preferem despachar o produto em embalagens de 15,0 kg, que são empilhadas, paletizadas (para uso da empilhadeira) e envolvida por um filme de PVC, para evitar variações no teor de umidade do produto. Entre os treze produtores de pellets, apenas um informou comercializar o produto na embalagem de $1,0 \mathrm{~kg}$, destinada ao mercado de granulados higiênicos para pequenos animais. Nessa aplicação excêntrica, a baixa umidade e as características adsortivas dos pellets de madeira permitem sua utilização como "areia de gato". As embalagens mais citadas pelos produtores foram os sacos de 15,0 kg e big bags de $750 \mathrm{~kg}$, utilizados por $70 \%$ e $50 \%$ dos produtores, respectivamente.

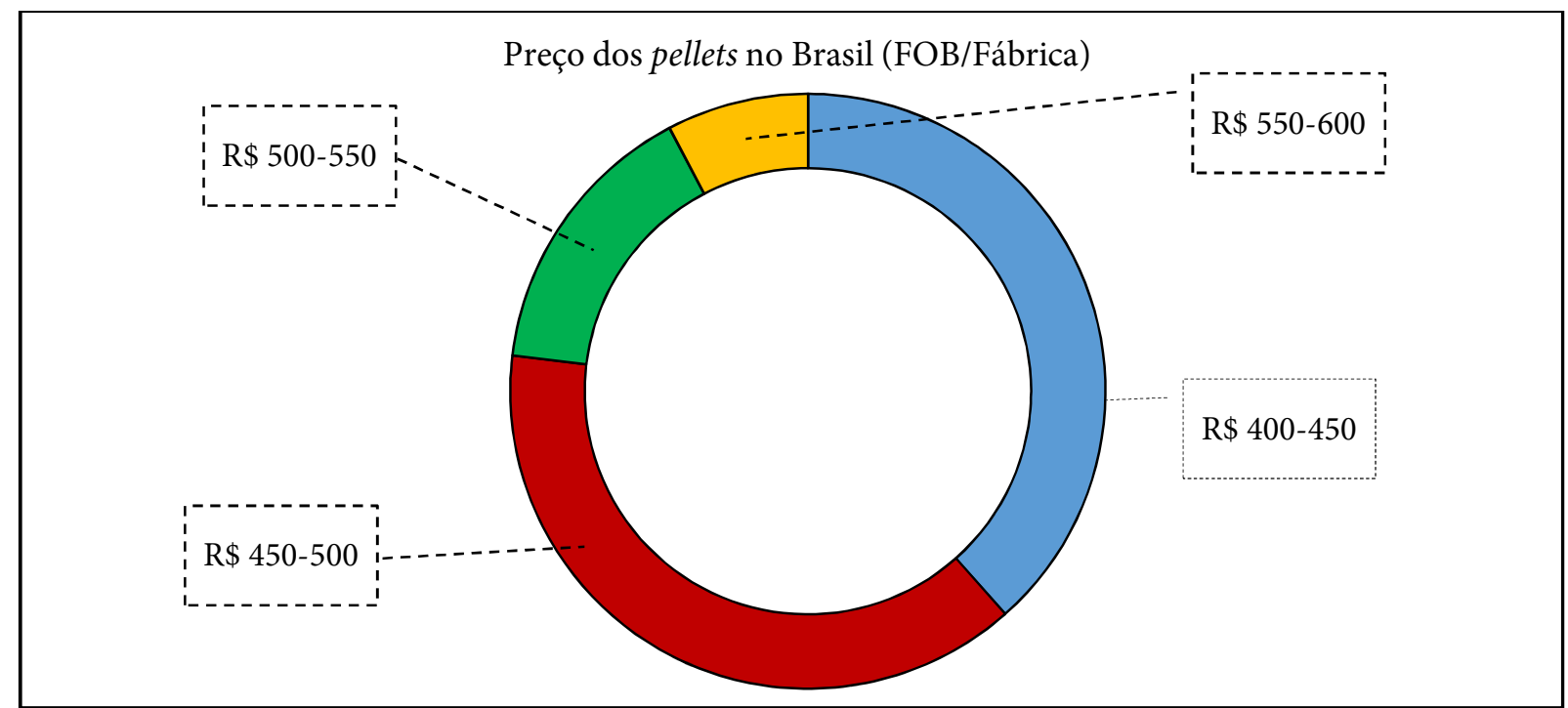

Figura 3. Preço dos pellets no Brasil (\% das empresas que os comercializam por esse valor).

Figure 3. Price of wood pellets in Brazil (\% of the companies that sell them by this value). 
Em 2015, o mercado interno brasileiro consumiu 57.698 toneladas de pellets, representando $76,93 \%$ da produção total do país. As principais aplicações são para a geração de energia térmica nas áreas comerciais e industriais, como o aquecimento de aviário, hotéis, pizzarias e padarias.

Quanto aos principais problemas do setor de pellets, $62 \%$ dos produtores apontaram a falta de clientes e de demanda interna como o mais significativo para as indústrias produtoras, seguido do custo alto da energia elétrica (54\%) e do desconhecimento do produto (46\%).

Quanto à falta de demanda interna, Garcia (2014a, 2014b); Tavares e Tavares (2015) relatam o lento desenvolvimento do mercado interno de pellets no Brasil e mencionam problemas estruturais, logísticos e culturais como fatores de destaque para isso. No entanto, o acordo global sobre mudanças climáticas (COP21) pediu a substituição de combustíveis fósseis por fontes renováveis e menos poluidoras. Assim, os pellets serão utilizados para o cumprimento das metas de redução das emissões assinadas no acordo, criando tendência positiva de crescimento das demandas para os próximos anos.

Quanto ao preço da energia elétrica, um problema estrutural do Brasil, para contornar o problema, as empresas já estão desenvolvendo projetos industriais mais compactos, que minimizam os gastos com energia causados pelo excesso de movimentação da matéria-prima na fábrica. Além disso, projetos de indústrias, com cogeração a partir da biomassa florestal, surgem como opção de energia elétrica mais barata para o processo produtivo.

Quanto ao desconhecimento do produto, é importante relatar que a indústria brasileira ainda é muito jovem, tem apenas 12 anos de existência. É necessário mais tempo para que empresários, consumidores e a sociedade em geral conheçam as vantagens econômicas e ambientais obtidas com a utilização dos pellets de madeira.

\section{Conclusões}

De acordo com os dados fornecidos pelos 13 produtores de pellets do Brasil, este estudo conclui que:

- O setor de pellets de madeira surgiu no país a partir do ano de 2004;

- Em 2015, as treze indústrias peletizadoras produziram 75.000 toneladas do produto;

- Os resíduos de Pinus (na forma de serragem, maravalha e pó de serra) são as principais matérias-primas utilizadas na produção de pellets;

- Em 2015, o mercado interno consumiu 76,93\% da produção brasileira de pellets e 17.302 toneladas foram exportadas.

- Os principais consumidores no mercado interno brasileiro são: aquecimento de aviário, hotéis, pizzarias e padarias.

- Em média, os pellets de madeira são comercializados por $\mathrm{R} \$ 471,15$ a tonelada (FOB);

- Os três principais problemas do setor de pellets, apontados pelos produtores, são: baixa demanda interna para o produto, custo alto da energia elétrica para a indústria e desconhecimento do produto pelos consumidores.

\section{Referências}

ADAMS, P. W. R.; LINDEGAARD, K. A critical appraisal of the effectiveness of UK perennial energy crops policy since 1990. Renewable and Sustainable Energy Reviews, v. 55, p. 188-202, 2016.

EUROPEAN BIOMASS ASSOCIATION - AEBIOM. Statistical Report 2015: European Bioenergy Outlook. European Pellet Council, v. 12, n. 1, p. 1-5, 2014.

BISWAS, A. K.; YANG, W.; BLASIAK, W. Steam pretreatment of Salix to upgrade biomass fuel for wood pellet production. Fuel Processing Technology, v. 92, n. 9, p. 17111717, 2011. 
M.M.; MIRANDA, C.H.B.; BARBOSA, P.F.D.; ROCHA, J.D. Produção de briquetes e péletes a partir de resíduos agrícolas, agroindustrais e florestais. $1^{\text {a }}$ ed. Brasília: Embrapa Agroenergia, 2012. 132p.

FORTI, R.; HEMRARD, M. Eurostat: Agriculture, forestry and fishery statistics: Roundwood, fuelwood and other basic products. Luxemburgo: EUROESTAT, 2014.

GARCIA, D. P.; CARASCHI, J. C.; VENTORIM, G. Caracterização energética de pellets de madeira. Revista da Madeira, v. 135, n. 2, p. 14-18, 2013.

GARCIA, D. P. Pellets de Madeira: Uma questão de competitividade e preço. Revista da Madeira, v. 138, n. 6, p. 35-38, 2014a.

GARCIA, D. P. Os desafios das indústrias de pellets de madeira: competitividade. Revista Opiniões, v. 12, p. 43-44, 2014b.

GARCIA, D. P.; CARASCHI, J. C.; VENTORIM, G. Decomposição térmica de pellets de madeira por TGA. Holos, v. 1, n. 32, p. 327-339, 2016 a.

GARCIA, D. P.; CARASCHI, J. C.; VENTORIM, G.; VIEIRA, F.H.A. Trends and challenges of origin brazilian agroforestry pellets industry. Cerne, v. 22, n. 3, p. 233-240, $2016 \mathrm{~b}$.

HEIDEMANN, L. A.; OLIVEIRA, A. M. M.; VEIT, E. A. Ferramentas on line no ensino de ciências: uma proposta com o Google Docs. Física na escola, v. 11, n. 2, p. 30-33, 2010.

HOLM, J. K.; HENRIKSEN, U.B.; HUSTAD, J.E.; SORENSEN, L.H. Toward an understanding of controlling parameters in softwood and hardwood pellets production. Energy and Fuels, v. 20, n. 1, p. 2686-2694, 2006.

INDÚSTRIA BRASILEIRA DE ÁRVORES - IBÁ. Indicadores de desempenho do setor nacional de árvores plantadas referentes ao ano de 2014. São Paulo, 2015. 100p.

INTERNATIONAL ORGANIZATION

FOR STANDARDIZATION. ISO 17225-2: 2014 - Solid biofuels Fuels especication and classes - Part 2 - Graded pellets. Brussels, 2014.

KONG, L.; XIONG, Y.; TIAN, S.; LI, Z.; LIU, T.; LUO, R. Intertwining action of additional fiber in preparation of waste sawdust for biofuel pellets. Biomass and Bioenergy, v. 59, p. 151-157, 2013.
LASCHI, A.; MARCHI, E.; GONZÁLEZ-GARCÍA, S. Environmental performance of wood pellets production through life cycle analysis. Energy, v. 103, p. 469-480, 2016.

LIU, H.; QIU, G.; SHAO, Y.; RIFFAT, S. B. Experimental investigation on flue gas emissions of a domestic biomass boiler under normal and idle combustion conditions. International Journal of Low-Carbon Technologies, v. 5, n. 2, p. 88-95, 2010.

OBERNBERGER, I.; THEK, G. Physical characterisation and chemical composition of densified biomass fuels with regard to their combustion behaviour. Biomass and Bioenergy, v. 27, n. 6, p. 653-669, 2004.

ÖHMAN, M.; BOMANA, C.; HEDMAN, H.; NORDIN, A. ; BOSTRÖM, D. Slag-ging tendencies of wood pellet ash during combustion in residential pellet burners. Biomass and Bioenergy, v. 27, n. 6, p. 585-596, 2004.

SCHNEIDER, V.E.; PERESIN, D.; TRENTIN, A.C.; BORTOLIN, T.A.; SAMBUICHI, R.H.R. Diagnóstico dos Resíduos Orgânicos do Setor Agrossilvopastoril e Agroindústrias Associadas - IPEA. Instituto de Pesquisa Econômica Aplicada, 2012. 134p.

SELKIMÄKI, M.; YUDEGO, B.M.; RÖSER, D.; PRINZ, R.; SIKANEN, L. Present and future trends in pellet markets, raw materials, and supply logistics in Sweden and Finland. Renewable and Sustainable Energy Reviews, v. 14, n. 9, p. 3068-3075, 2010.

SERRANO, C.; MONEDERO, E.; LAPUERTA, M.; PORTERO, H. Effect of moisture content, particle size and pine addition on quality parameters of barley straw pellets. Fuel Processing Technology, v. 92, n. 3, p. 699-706, 2011.

SHAHRUKH, H.; OYEDUN, A.O.; KUMAR, A.; GHIASI, B.; KUMAR, L.; SOKHANSANJ, S. Techno-economic assessment of pellets produced from steam pretreated biomass feedstock. Biomass and Bioenergy, v. 87, p. 131143, 2016.

TAVARES, M. A. M. E.; TAVARES, S. R. L. Perspectivas para a participação do Brasil no mercado Internacional de pellets. Holos, v. 5, n. 31, p. 292-306, 2015.

TOSCANO, G.; DUCA, D.; AMATO, A.; PIZZI, A. Emission from realistic utilization of wood pellet stove. Energy, v. 68, n.15, p. 644-650, 2014.

VASSILEV, S. V. ; BAXTER, D.; ANDERSEN, L.K.; 
VASSILEVA, C.G. An overview of the chemical composition of biomass. Fuel, v. 89, n. 5, p. 913-933, 2010.

VERMA, V. K.; BRAM, S.; DELATTIN, F.; LAHA, P.; VANDENDAEL, I.; HUBIN, A.; DE RUYCK, J. Agro-pellets for domestic heating boilers: Standard laboratory and real life performance. Applied Energy, v. 90, n. 1, p. 17-23, 2012. 